\title{
Effect of Acidic Agents on Microhardness and Surface Morphology of Two Metal Ceramic Materials: An In Vitro Study
}

\author{
Shanthi Priya $K^{1}$, M Praveen Kumar ${ }^{2}$, V Pridhvi Krishna ${ }^{3}$, P Lakshmaiah $^{4}$, Manasa Chalapathi ${ }^{5}$, Ganji Devi $^{6}$
}

\begin{abstract}
Aim: The aim of the present study was to evaluate the effect of acidic agents on microhardness and surface morphology of two metal ceramic materials at various intervals.

Materials and methods: A total of 120 metal ceramic disks were prepared and divided into two categories with 60 each. Each category was divided into two groups, group I (Made of IPS d.SIGN) and group II (made of VITA VMK), containing 30 samples each, which was subdivided into three subgroups each containing 10 samples $\mathrm{A}$ (i) $\mathrm{B}$ (i) acting as control, $\mathrm{A}$ (ii) $\mathrm{B}$ (ii) immersed in $0.5 \% \mathrm{HCl}$, and $\mathrm{A}$ (iii) $\mathrm{B}$ (iii) immersed in soft cola drink. Group I was tested for microhardness with Vickers microhardness testing machine at an interval of 0 minute, 24 hours, and 168 hours after immersing in acidic agents. Group II was observed for surface morphology changes with scanning electron microscope before immersion, and at an interval of 24 hours and 168 hours after immersing in acidic agents. The results were analyzed statistically, tabulated, and compared. Results: Results revealed that there was a significant decrease in microhardness of IPS d.SIGN and VITA VMK when immersed in acidic agents at an interval of 0 minute, 24 hours, and 168 hours. There were significant surface morphological changes too of both the ceramics before and after immersing in acidic agents at 24 hours and 168 hours.

Conclusion: Acidic agents evaluated in the present study affected microhardness and surface morphology of both the ceramics, and IPS d.SIGN is the most suitable and would be recommended in people who consume acidic beverages.

Clinical significance: Durability of dental ceramics is very good, but degradation occurs when exposed to acidic agents. All the properties of ceramics are to be known in depth as they are widely used to construct various types of prostheses, and this has to be considered especially in people who consume acidic foods and drinks.
\end{abstract}

Keywords: Acidic agents, Metal ceramics, Microhardness, Surface morphology.

The Journal of Contemporary Dental Practice (2019): 10.5005/jp-journals-10024-2690

\section{INTRODUCTION}

Dental ceramics are used to construct different type of prosthesis like veneers, crowns, and FPD in prosthodontics. ${ }^{1}$ Excellent biocompatibility, resistance to wear, chemical inertness, and high aesthetic qualities are attributed to their high demand in dentistry. ${ }^{2-4}$ Even though all ceramic materials are introduced as more aesthetic materials these days, porcelain fused to metal restorations are frequently used due to their excellent fracture resistance and low cost compared to all ceramic materials. ${ }^{5}$

Dental ceramics are highly susceptible to fracture, ${ }^{6,7}$ as they exhibit inherent flaws on the surface and thus impair physical properties like surface roughness, surface hardness, and strength, ${ }^{8,9}$ which influence the clinical success and failure of ceramic restorations. ${ }^{10}$

Degradation of dental ceramics occur by selective leaching of alkali ions ${ }^{11-13}$ when exposed to acidic agents, and the amount of degradation depends on the type of ceramic and it is more in carbonated beverages than in water. ${ }^{14}$

Dental erosion is commonly seen in people who regularly consume acidic foods or with gastrointestinal disturbances. ${ }^{15,16}$ There would be dissolution of surface apatite crystals of enamel due to this erosion. ${ }^{17-19}$

Therefore, the aim of the present study was to evaluate the changes of microhardness of two metal ceramics after immersing in acidic agents at an interval of 0 minute, 24 hours, and 168 hours, and surface morphology changes before immersion
1-3,6 Department of Prosthodontics and Crown and Bridge, MNR Dental College and Hospital, Sangareddy, Telangana, India

${ }^{4}$ Department of Prosthodontics and Crown and Bridge, Narayana Dental College and Hospital, Nellore, Andhra Pradesh, India

${ }^{5}$ Department of Prosthodontics and Crown and Bridge, S Nijalingappa Institute of Dental Science and Research, Gulbarga, Karnataka, India

Corresponding Author: Shanthi Priya K, Department of Prosthodontics and Crown and Bridge, MNR Dental College and Hospital, Sangareddy, Telangana, India, Phone: +919949919751, e-mail: kota.shanthi@ gmail.com

How to cite this article: Priya KS, Kumar MP, Krishna VP, et al. Effect of Acidic Agents on Microhardness and Surface Morphology of Two Metal Ceramic Materials: An In Vitro Study. J Contemp Dent Pract 2019;20(11):1329-1334.

Source of support: Nil

Conflict of interest: None

and after immersing in acidic agents at an interval of 24 hours and 168 hours.

\section{Materials and Methods}

This in vitro study was conducted in MNR Dental College and Hospital, Sangareddy, India. A total of 120 base metal (nickel 
chromium alloy) disks with a thickness of $0.5 \mathrm{~mm}$ were made by following conventional casting technique after the fabrication of wax patterns using depth micrometer. The opaque, dentin porcelain followed by glaze firings in Singlemat ceramic furnace as per manufacture instructions. They were divided into two categories. Category I was made up of IPS d.SIGN (IVOCLAR VIVADENT), and category II was made up of VITA VMK (VITA) each containing 60 samples. Each category was divided into two groups: group I containing 30 samples which were tested for microhardness were subdivided into three sub groups each containing 10 samples- $A(i)$ acting a control, $\mathrm{A}$ (ii) immersed in $0.5 \% \mathrm{HCl}$, and $\mathrm{A}$ (iii) immersed and soft cola drink. Group II containing 30 samples were subdivided into three subgroups each containing 10 samples-B(i) acting as control, B(ii) and $\mathrm{B}$ (iii) containing 10 samples were treated with $0.5 \% \mathrm{HCl}$ and soft cola drink as shown in Table 1 and Figure 1. The immersion agents used in the study were distilled water (control), $0.5 \% \mathrm{HCl}$, and soft cola drink.

Group I samples were analyzed for microhardness with BUEHLER Vickers microhardness testing machine at surface engineering group, Defence Research and Development Organisation, Kanchanbagh, Hyderabad. The value of indentation load was such that indentation prints were crackless and at the same time easily measurable. Each specimen was placed on the test table, and after adjusting the table, diamond with as square-based pyramid was forced onto the specimen with a load of $200 \mathrm{~g}$ for 15 seconds with a diamond tip. After withdrawing the indenter, the projected area is viewed under microscope at $200 \times$ magnification, and the indentation diagonals were measured and area calculated. Three readings were calculated for each specimen ensuring that the surface of the specimens was representative. Vickers microhardness number (VHN) was calculated using the formula $\mathrm{VHN}=$ load/area on indentation at an interval of 0 minute, 24 hours, and 168 hours after immersing in acidic agent solutions.

Group II samples were analyzed for surface morphology before immersion and at an interval of 24 hours and 168 hours after immersion in acidic agent solution (Fig. 2). The samples were rinsed with distilled water for 5 minutes, dried and fixed onto aluminum cylinder. Then they were sputter coated with a gold palladium alloy for 8 minutes and examined under scanning electron microscope (ZIESS) for surface morphology changes $(\times 2,000$ magnification)

Based on the nature of the surface of the sample after immersion under the SEM, they were graded in to mild, moderate, and severe.

Grade I (mild): Smooth and dense surface with very few porosities. Grade II (moderate): Irregular surface with numerous porosities. Grade III (severe): Degraded surface with voids channels and numerous distinguishable microundercuts.

Table 1: Division of specimens

\begin{tabular}{|c|c|c|}
\hline Categories & Groups & Subgroups \\
\hline \multirow[t]{6}{*}{ IPS d.SIGN-I (IVOCLAR) $(n=60)$} & \multirow[t]{3}{*}{ Group I ( $n=30$ ) (for microhardness) } & $\mathrm{Ai}(n=10)$ distilled water \\
\hline & & Aii $(n=10) 0.5 \% \mathrm{HCl}$ \\
\hline & & Aiii $(n=10)$ soft cola drink \\
\hline & \multirow[t]{3}{*}{ Group II ( $n=30$ ) (for surface morphology) } & $\mathrm{Bi}(n=10)$ distilled water \\
\hline & & $\mathrm{Bii}(n=10) 0.5 \% \mathrm{HCl}$ \\
\hline & & Biii $(n=10)$ soft cola drink \\
\hline \multirow[t]{6}{*}{ VITA VMK-II $(n=60)$} & \multirow[t]{3}{*}{ Group I ( $n=30)$ (for microhardness) } & $\mathrm{Ai}(n=10)$ distilled water \\
\hline & & Aii $(n=10) 0.5 \% \mathrm{HCl}$ \\
\hline & & Aiii $(n=10)$ soft cola drink \\
\hline & Group II ( $n=30$ ) (for surface morphology) & $\mathrm{Bi}(n=10)$ distilled water \\
\hline & & $\mathrm{Bii}(n=10) 0.5 \% \mathrm{HCl}$ \\
\hline & & Biii $(n=10)$ soft cola drink \\
\hline
\end{tabular}

$n$, number of sample

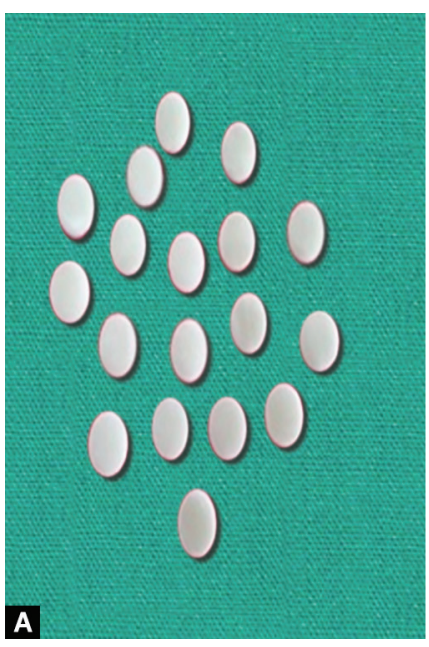

Figs 1 A and B: (A) Specimens of IPS d.SIGN; (B) Specimens of VITA VMK

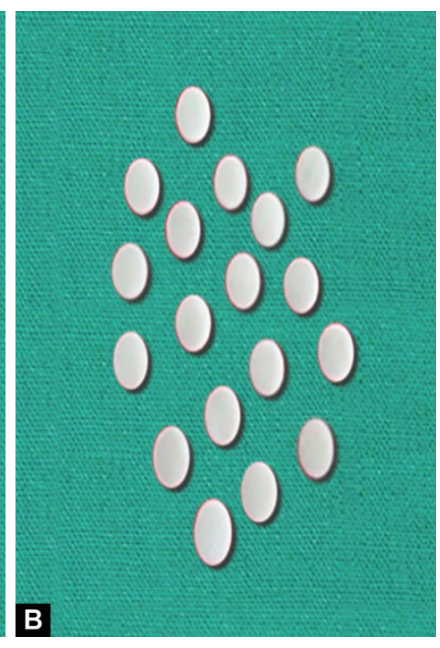

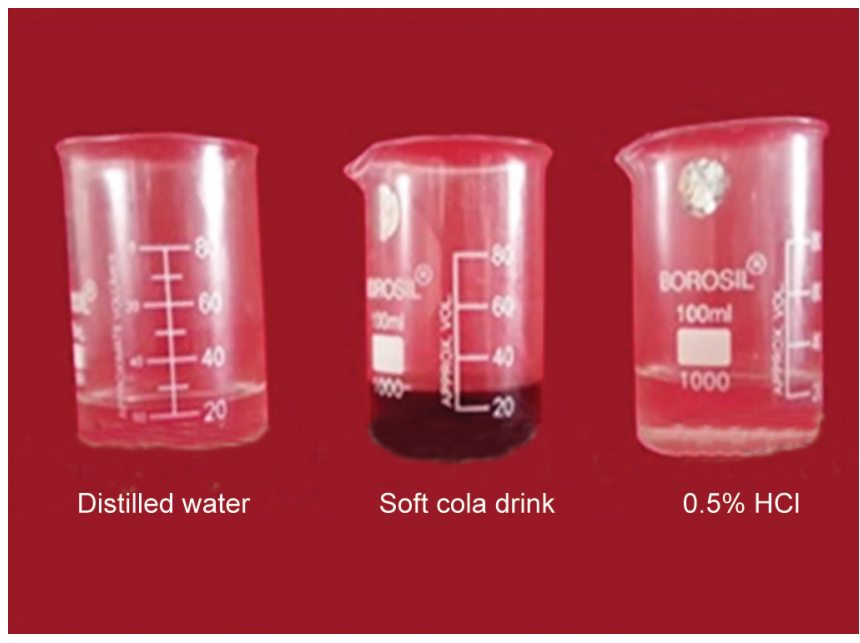

Fig. 2: Acidic agent solutions 


\section{Statistical Analysis}

In the present study, $p$ value $<0.05$ was considered as the level of significance. The data were statistically analyzed using SPSS version 22 (IBM Corporation Washington DC, United States) and one-way analysis of variance (ANOVA) for hardness, indicating that statistically significance differences existed among subgroup means at various intervals when immersed in acidic agents.

As SEM study was a qualitative study, Mann-Whitney $U$ test was performed to determine the effect of acidic agents on surface morphology at various intervals.

\section{Results}

In the present study, the Vickers microhardness values of specimens after immersing in acidic agents have shown a decrease in hardness than the control group in both the categories at different intervals. As described in Table 2, the mean microhardness of IA(i) which acted as control was (531.60 VHN at 0 minute), (530.92 VHN at 24 hours), and (479.14 VHN at 168 hours) and in subgroup IA(ii) which were immersed in $0.5 \% \mathrm{HCl}$ it was (507.94 VHN at 0 minute), (481.74 VHN at 24 hours), and ( $354.17 \mathrm{VHN}$ at 168 hours) whereas in subgroup IA(iii) which were immersed in soft cola drinks was (504.24 VHN at 0 minute), (470.26 VHN at 24 hours), and (3,98,094 VHN at 168 hours).

As described in Table 3, the mean microhardness of IIA(i)which acted as control was (492.02 VHN at 0 minute), (487.52 VHN at 24 hours), (485.33 VHN at 168 hours), and in subgroup IIA(i) which were immersed in $0.5 \% \mathrm{HCl}$ was (488.22 $\mathrm{VHN}$ at 0 minute), (462.65 VHN at 24 hours), (356.02 VHN at 168 hours) and in subgroup IIA(iii) it was (486.68 VHN at 0 minute), (445.76 VHN at 24 hours), and (388.37 VHN at 168 hours).

SEM analysis showed the surfaces with alterations, irregularities, and pores at varying degrees. Such surface patterns were more evident in these ceramics as they contained leucite particles in their composition.

Statistical analysis revealed that there was a significant difference with in the categories at various intervals after immersing in acidic agents. Control group of VITA VMK displayed a smooth and dense surface with very little porosities and that of IPS $d$.SIGN displayed peculiar needle-like crystals in a dense matrix, and these were seem to be fluroapatite crystals which were disappeared after immersing in acidic agents.
There was more degradation of surface with voids and channels at various intervals when immersed in $0.5 \% \mathrm{HCl}$ when compared to both control group (distilled water) and soft cola drink.

Hence, there were significant surface morphological changes of IPS d.SIGN as shown in Figure 3 and VITA VMK as shown in Figure 4. (Figs $3 \mathrm{~A}$ and $4 \mathrm{~A}$ before immersion, Figs $3 \mathrm{~B}$ and $4 \mathrm{~B}$ when immersed in $0.5 \% \mathrm{HCl}$ at 168 hours, Figs $3 \mathrm{C}$ and $4 \mathrm{C}$ when immersed in soft cola drink at 168 hours).

\section{Inference}

There was a statistical significant decrease in mean microhardness values and surface morphological changes within the same group when immersed in $0.5 \% \mathrm{HCl}$ and soft cola drink.

\section{Discussion}

Hardness is a measure of resistance to permanent indentation. The Vickers microhardness (VHN) test quantifies the hardness and is measured according to the depth of indentation of a diamond pyramid. ${ }^{20}$

Durability of dental ceramics is very good and is influenced by factors such as the composition and the microstructure of ceramic material, the chemical character of corrosive medium, the exposure time, and the temperature., ${ }^{1,3}$

The acidic agents used in the study were $0.5 \% \mathrm{HCl}$ and soft cola drink whose $\mathrm{pH}$ was below 3.5. Specific interest in selecting these agents was that cola is one of the most consumed soft drinks, consists of carbonic and citric acid, and is therefore highly acidic drink. $0.5 \% \mathrm{HCl}$ is the main acid present in the gastric juice and its regurgitation into the oral cavity was the common symptom among the people having upper alimentary tract diseases. These acids might cause the elemental dissolution of ceramics due to its chelating effect.

The degradation of ceramics generally occurs because of mechanical factors or chemical attack. The possible physiologic side effects on ceramic materials due to this are their tendency to abrade opposing dental structures, emission of ions which may influence further degradation, the roughening of surface leading to plaque retention. Due to this degradation, there is dissolution of glass network leading to crack growth, ${ }^{21}$ non uniform stress distribution, ${ }^{8}$ effecting the mechanical properties such as hardness,

Table 2: The mean microhardness values of IPS d.SIGN (category I) when immersed in acidic agents at various intervals

\begin{tabular}{|c|c|c|c|c|c|c|c|}
\hline Storage agent & \multicolumn{2}{|c|}{ O minute } & \multicolumn{2}{|c|}{24 hours } & \multicolumn{2}{|c|}{168 hours } & $p$ value \\
\hline Distilled water (I) Ai & 531.60 & 63.89 & 530.92 & 42.15 & 479.14 & 39.25 & 0.392 not significant \\
\hline $0.5 \% \mathrm{HCl}(\mathrm{I}) \mathrm{Aii}$ & 507.94 & 15.08 & 481.74 & 24.17 & 354.17 & 46.99 & 0.000 significant \\
\hline Cola drink (I) Aiii & 504.24 & 23.40 & 470.26 & 31.00 & 398.94 & 27.88 & 0.000 significant \\
\hline
\end{tabular}

Statistically significant $=p<0.05$

Table 3: The mean microhardness values of VITA VMK (category II) before and after immersing acidic agents at different intervals

\begin{tabular}{|c|c|c|c|c|c|c|c|}
\hline \multirow[b]{2}{*}{ Storage agent } & \multicolumn{2}{|c|}{0 minute } & \multicolumn{2}{|c|}{24 hours } & \multicolumn{2}{|c|}{168 hours } & \multirow[b]{2}{*}{$p$ value } \\
\hline & Mean & $S D$ & Mean & $S D$ & Mean & $S D$ & \\
\hline Distilled water IIA(i) & 492.02 & 34.46 & 487.52 & 24.68 & 485.33 & 8.90 & 0.831 not significant \\
\hline $0.5 \% \mathrm{HCl} ॥ \mathrm{~A}(\mathrm{ii})$ & 488.22 & 17.36 & 462.65 & 35.11 & 356.02 & 36.44 & 0.000 significant \\
\hline Cola drink IIA(iii) & 486.68 & 31.58 & 445.76 & 29.77 & 388.37 & 23.63 & 0.000 significant \\
\hline
\end{tabular}

Statistically significant $=p<0.05$ 

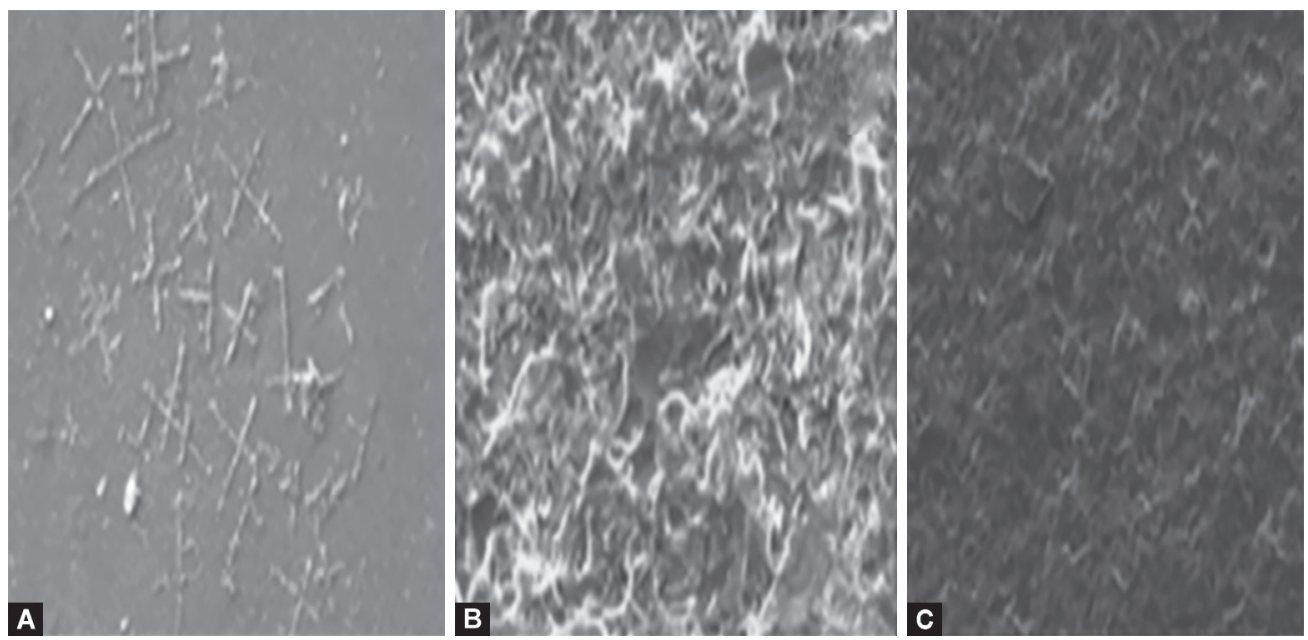

Figs $3 \mathrm{~A}$ to C: SEM photomicrograph of IPS d.SIGN: (A) Before immersion; (B) When immersed $0.5 \% \mathrm{HCl}$ at 168 hours; (C) When immersed in cola drink at 168 hours
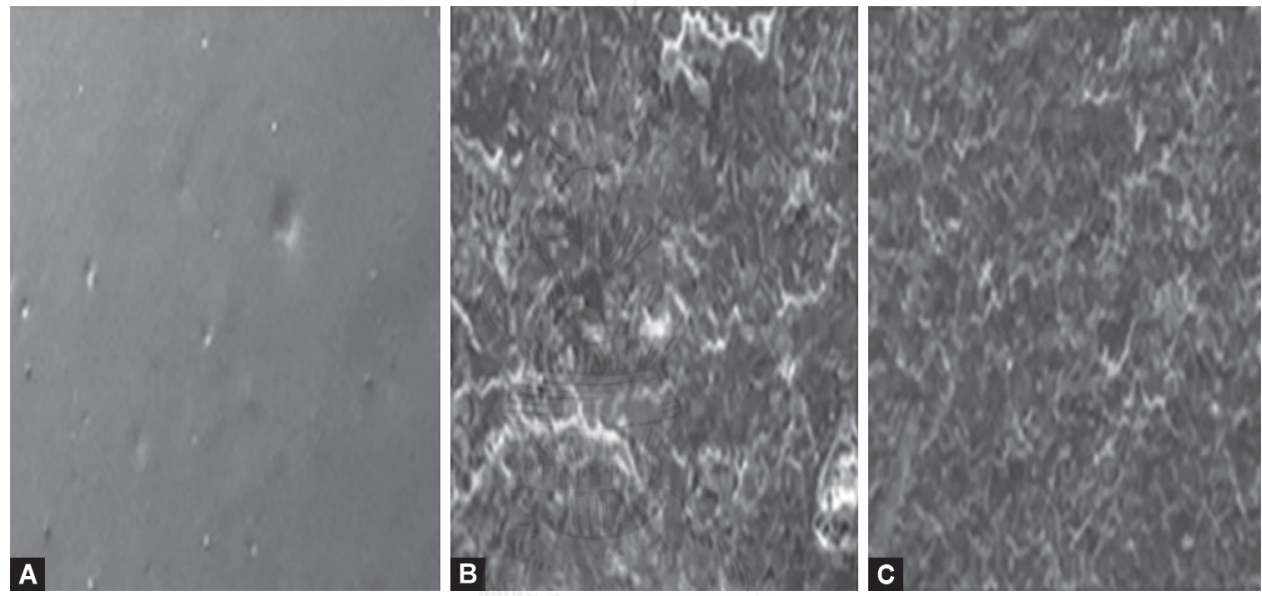

Figs 4A to C: SEM photomicrograph of VITA VMK: (A) Before immersion; (B) When immersed $0.5 \% \mathrm{HCl}$ at 168 hours; (C) When immersed in cola drink at 168 hours

which is the predictor of abrasiveness, fracture toughness, ${ }^{22}$ flexural strength, etc.

Dental erosion is the wear of dental hard tissues by acids. It is an irreversible condition caused by intrinsic factors like acid reflux seen in gastrointestinal disturbances and extrinsic factors like soft cola drinks which are commonly consumed. There would be dissolution of hydroxyapatite present in the enamel which is seen immediately after consuming acid beverages. ${ }^{23}$ The dissolution of enamel depends on the duration and frequency of acid reflux. ${ }^{24}$

Acidic beverages which are routinely consumed also effected the ceramic surface due to loss of ions from the surface and amount being dependent on the type of ceramic, ${ }^{3}$ wear of ceramic being more in carbonated beverages than in water. ${ }^{14}$

Fluroapatite ceramics were the best among the tested ceramics as the fluroapatite particle contribute to high chemical durability. Feldspathic ceramic contains leucite particles which contract more when compared to glass that is surrounding it when ceramic is cooled during firing stage. Susceptibility of ceramics to acids is increased, which results in decreased microhardness due to microcracks that are a result of stress during cooling of ceramics. $^{2}$
According to Junpoom et al., the two mechanisms that are responsible for decrease in microhardness are (a) leaching of alkali ions and (b) glass network dissolution, and this mechanism is controlled by interchange of alkali ions and $\mathrm{H}^{+}$ions, and $\mathrm{H}_{3} \mathrm{O}^{+}$ ions between glass and aqueous solution and are leached out. ${ }^{19}$

The present study is supported by the study conducted by Kukiattrakoon et al. ${ }^{25,26}$ who evaluated different acidic agents and their effect on various properties of dental porcelain. All four types of dental porcelains tested were affected by the acidic agents, and fluroapatite porcelain would be the most appropriate one in case of people who regularly consume acidic beverages. ${ }^{25,26}$

The findings of the present study were supported by Kukiattrakoon et al. ${ }^{1,4}$ who evaluated different naturally occurring acidic agents on properties of fluroapatite-leucite ceramics and concluded that there was a significant decrease in microhardness and also the weight percentages of silicon, potassium, aluminum, and sodium after immersion.

A similar study done by $\mathrm{Yu}$ et al. $^{27}$ on polymer infiltrated ceramics and their wear behavior concluded that acid erosion decreased the surface microhardness and increased surface roughness and it is in favor with the present study. 
The results of the present study are supported by the studies conducted by Denry et al., ${ }^{28}$ Eleana et al., ${ }^{29}$ and Vechiato-Filho et al. ${ }^{30}$

A study done by Al-Hiyasat et al. ${ }^{31}$ is similar to the present study and also in favor which concluded that Coca-Cola not only contributed to the enamel wear by demineralizing the tooth and making it susceptible to the abrasive effect of the ceramic materials but also effected the wear of the ceramic material.

SEM analysis showed the surfaces with alterations, irregularities, and pores at varying degrees. There was more degradation of surface with voids and channel at various interval when immersed in $0.5 \% \mathrm{HCl}$ when compared to both control group (distilled water) and soft cola drinks, and this might be due to more aggressive nature of $\mathrm{HCl}$ whose $\mathrm{pH}$ was low when compared to cola drink and is this caused the dissolution of crystalline structure leading to this appearance and loss of particles from its composition. Similar changes were seen in study conducted by Sinmazisik et al. ${ }^{32}$

The results of this study are supported by the study done by Kukiattrakoon et al. ${ }^{4,19,25,26}$ on dental porcelains surface features due to the acidic agents who stated that SEM pictures of VITA VMK immersed in different acidic agents showed various patterns. Before immersion, surface was dense with little porosity; in deionized water, surface showed a little porosity; there were numerous porosities on the surface immersed in citrate solution and green mango juice; in pineapple juice, surface exhibited the degradation with numerous porosities, and in acetic acid, there were small cracks with surface degradation.

The results of this study are supported by the study conducted by Percy et al..$^{19,33}$ on surface corrosion of dental ceramics who stated that the traditional leucite containing ceramics display an obvious surface deterioration dominated by differently sized porosities and voids whereas microleucite and nonleucite dental ceramic materials display a fairly smooth surface with spherical porosities.

Canay et al. ${ }^{34}$ studied the effect of different acid treatments on the surface of porcelain and concluded that the surface was homogenously smooth when etched with APF acid and it was more pronounced and aggressive when etched with HF depending on the period of etching ranging from voids and channels to surface with numerous distinguishable microundercuts.

More degradation of category II when compared to category I was due to heterogenous crystalline nature of VITA VMK.

In this study, only microhardness and surface morphology were used as parameters to evaluate the degradation of metal ceramics. Additional methods such as depth analysis, surface roughness, and elements released into acidic agents need to be employed to further confirm the results of the present study. As it was an in vitro study, further studies are recommended to explain the degradation effect in vivo and also on other types of ceramics.

\section{Conclusion}

Within the limitations of the study, it was concluded that

- The acidic agents $(0.5 \% \mathrm{HCl}$, soft cola drink) evaluated had an adverse effect on both the microhardness and surface morphology of the two metal ceramic materials.

- Fluroapatite leucite ceramics (IPS d.SIGN) are the most suitable and recommended for the restorations in people who consume acidic beverages.

\section{References}

1. Kukiattrakoon $B$, Junpoon $P$, Hengtrakool C. Vickers microhardness and energy dispersive $\mathrm{X}$-ray analysis of fluorapatiteleucite and fluorapatite ceramics cyclically immersed in acidic agents. J Oral Sci 2009;51(3):443-450. DOI: 10.2334/josnusd.51.443.

2. Raptis NV, Michalakis KX, Hirayama H. Optical behavior of current ceramic systems. Int J Periodontcs Restorative Dent 2006;26(1):31-41.

3. Milleding P, Haraldsson C, Karlsson S. Ion leaching from dental ceramics during in vitro corrosion testing. J Biomed Mater Res 2002;61(1):541-550. DOI: 10.1002/jbm.10109.

4. Kukiattrakoon B, HengtrakoolC, Leggat UK. Degradability of fluorapatite-leucite ceramics in naturally acidic agents. Dent Mater 2010;29(5):502-511. DOI: 10.4012/dmj.2009-111.

5. Philips AKJ. Science of dental materials. 11th ed., Philadelphia: WB Saunders Co; 2006. pp. 655-719.

6. Haselton DR, Diaz-Arnold AM, Hillis SL. Clinical assessment of highstrength all ceramic crowns. J Prosthet Dent 2000;83(4):396-401. DOI: 10.1016/S0022-3913(00)70033-3.

7. Kelly JR, Giordano R, Pober R, et al. Fracture surface analysis of dental ceramics: clinically failed restorations. Int J Prosthodont 1990;3(5):430-440.

8. de Jager N, Feilzer AJ, Davidson CL. The influence of surface roughness on porcelain strength. Dent Mater 2000;16(6):381-388. DOI: 10.1016/S0109-5641(00)00030-0.

9. Fisher $\mathrm{H}$, Schafer $\mathrm{M}, \mathrm{Marx}$ R. Effect of surface roughness on flexural strength of veneer ceramics. J Dent Res 2003;82(12):972-975. DOI: 10.1177/154405910308201207.

10. Goodacre CJ, Bernal G, Rungcharassaeng K, et al. Clinical complications in fixed prosthodontics. J Prosthet Dent 2003;90(1): 31-41. DOI: 10.1016/S0022-3913(03)00214-2.

11. Anusavice KJ. Degradability of dental ceramics. Adv Dent Res 1992;6:82-89. DOI: 10.1177/08959374920060012201.

12. Jakovac M, Zivko-Babc J, Curkovic L, et al. Measurement of ion elution from dental ceramics. J Eur Ceram Soc 2006;26(9):1695-1700. DOI: 10.1016/j.jeurceramsoc.2005.03.242.

13. Jakovac M, Zivko-Babc J, Curkovic L, et al. Chemical durability of dental ceramic material in acid medium. Actastomatol Croat 2006;40(1):65-71.

14. Copps DP, Lacy AM, Curtis T, et al. Effect of topical fluorides on five low fusing dental porcelains. J Prosthet Dent 1984;52(3):340-343. DOI: 10.1016/0022-3913(84)90440-2.

15. Jaeggi T, Lussi A. Prevalence, incidence and distribution of erosion. Monogr Oral Sci 2006;20:44-65. DOI: 10.1159/000093350.

16. Khan F, Young WG, Law V. Cupped lesions of early onset dental erosion in young southeast Queensland adults. Aust Dent J 2001;46:100-107. DOI: 10.1111/j.1834-7819.2001.tb00564.x.

17. Imfeld T. Dental erosion. Definition, classification and links. Eur J Oral Sci 1996;104:151-155. DOI: 10.1111/j.1600-0722.1996.tb00063.x.

18. Kukiattrakoon B, Hengtrakool C, Kedjarune-Leggat U. Effect of acidic agents on surface roughness of dental ceramics. Dent Res J (Isfahan) 2011;8(1):6-15.

19. Junpoom P, Kukiattrakoon B, Hengtrakool C. Surface characteristic changes of dental ceramics after cyclic immersion in acidic agents and titratable acidity. Eur J Prosthodont Restor Dent 2010;18(4): 177-184.

20. Baharav $H$, Laufer BZ, Pilo R, et al. Effect of glaze thickness on the fracture toughness and hardness of alumina-reinforced porcelain. JProsthet Dent 1999;81(5):515-519. DOI: 10.1016/S0022-3913(99)70204-0.

21. Pinto MM, Cesar PF, Rosa V, et al. Influence of pH on slow crack propagation of dental porcelains. Dent mater 2008;24(6):814-823. DOI: 10.1016/j.dental.2007.10.001.

22. Powers JM, Sakaguchi RL. Craig's restorative dental materials, 12th ed., Mosby; 2006.

23. Grenby TH, Phillips A, Desai T, et al. Laboratory studies of the dental properties of soft drinks. British J Nutrition 1989;62(2):451-464. DOI: 10.1079/BJN19890045.

24. Jarvinen $\mathrm{V}$, Meurman $\mathrm{JH}$, Hyvarinen $\mathrm{H}$, et al. Dental erosion and upper gastrointestinal disorders. Oral surg Oral Med Oral Pathol 1988;65(3):298-303. DOI: 10.1016/0030-4220(88)90113-2.

25. Kukiattrakoon B, Hengtrakool C, Leggat UK. The effect of acidic agents on surface ion leaching and surface characteristics of dental 
porcelains. J Prosthet Dent 2010;103(3):148-162. DOI: 10.1016/S00223913(10)60021-2.

26. Kukiattrakoon B, Hengtrakool C, Leggat UK. Elemental release and surface changes of fluorapatite- leucite porcelain upon immersion in acidic agents. J Dent Sciences 2010;5(4):189-200. DOI: 10.1016/ j.jds.2010.11.003.

27. Yu P, Xu Z, Arola DD, et al. Effect of acidic agents on the wear behavior of a polymer infiltrated ceramic network (PICN) material. J MechBehav Biomed Mater 2017;74:154-163. DOI: 10.1016/j.jmbbm.2017.06.001.

28. Denry IL, Holloway JA. Elastic constants, Vickers hardness and fracture toughness of flurrichterite based glass ceramics. Dent Mater 2004;20(3):213-219. DOI: 10.1016/S0109-5641(03)00094-0.

29. Kontonasaki E, Kantiranis N, Papadopoulou L, et al. Micro structural characterization and comparative evaluation of physical, mechanical and biologic properties of three ceramics for metal-ceramic restorations. Dent Mater 2008;24(10):1362-1373. DOI: 10.1016/ j.dental.2008.03.002.
30. Vechiato-Filho AJ, Dos Santos DM, Goiato MC, et al. Surface degradation of lithium disilicate ceramic after immersion in acid and fluoride solutions. Am J Dent 2015;28(3):174-180.

31. Al-Hiyasat AS, Saunders WP, Sharkey SW, et al. The effect of carbonated beverage on wear of human enamel and dental ceramics. J Prosthodont 1998;7(1):2-12. DOI: 10.1111/j.1532-849X.1998. tb00169.x.

32. Sinmazisik G, Ovecoglu ML. Physical properties and micro structural characterization of dental porcelains mixed with distilled water and modeling liquid. Dent Mater 2006;22(8):735-745. DOI: 10.1016/ j.dental.2005.08.007.

33. Milleding $\mathrm{P}$, Wennerberg $\mathrm{A}$, Alaeddin S. Surface corrosion of dental ceramics in vitro. Biomaterials 1999;20(8):733-746. DOI: 10.1016/ S0142-9612(98)00223-3.

34. Canay S, Hersek N, Ertan A. Effect of different acid treatments on a porcelain surface. J Oral Rehabil 2001;28(1):95-101. DOI: 10.1046/j.1365-2842.2001.00626.x. 